\title{
Mycotoxins and Fungal Damage in Maize Harvested during 1982 in Far North Queensland
}

\author{
B. J. Blaney, C. J. Moore and A. L. Tyler \\ Queensland Department of Primary Industries, \\ Animal Research Institute, Yeerongpilly, Qld 4105.
}

\begin{abstract}
A survey for mycotoxins and fungal damage in maize (Zea mays L.) grown during 1982 in Far North Queensland is reported. This season had a rainfall distribution which was typical for the region. The 293 samples examined came from 111 farms in eight maize-growing districts. The samples were first subjected to rapid screening tests for fungal damage. Aflatoxins $B_{1}, B_{2}, G_{1}, G_{2}$, ochratoxin $A$, $T-2$ toxin, and sterigmatocystin were not detected, but zearalenone was found in $85 \%$ of the samples. The concentrations of zearalenone were correlated with the extent of Gibberella zeae cob rot as indicated by the proportion (up to $2 \%$ ) of kernels in each sample having a reddish-purple discoloration. In four samples the zearalenone concentration exceeded $1 \mathrm{mg} \mathrm{kg}^{-1}$, but the mean \pm s.d. $(n=293)$ concentration in all samples was $0 \cdot 17 \pm 0.225 \mathrm{mg} \mathrm{kg}^{-1}$. Concentrations were highest in districts with the highest rainfall during the period of maize growth.
\end{abstract}

\section{Introduction}

The degree of mycotoxin contamination of maize is influenced by the fungal population of the crop in the particular region in which it is grown and by the climate during the growth and maturation period. In livestock, epidemics arising from mycotoxin contamination of maize in North America have included those due to aflatoxin (produced by Aspergillus flavus Link ex Fries) in the south-east of the United States of America, particularly during the drought year of 1977 (Brown 1977), and those in 1965 and 1972 in Indiana due to deoxynivalenol (vomitoxin) and zearalenone (Tuite et al. 1974). These latter toxins can be produced by Fusarium graminearum Schwabe, also called Gibberella zeae (Schwabe) Petch in its perithecial state. Despite the seasonal nature of such epidemics, regions of high risk are likely to have a small degree of contamination in years when no disease in livestock is observed. Surveys can thereby help identify high risk regions.

Maize is grown in Australia primarily in the Burnett, Moreton, Darling Downs and Far North regions of Queensland, and in the North Coast region of New South Wales. The only previously reported survey of maize for mycotoxins in Australia (Blaney 1981) was in the Burnett region of Queensland, which is subject to frequent droughts.

The climate of maize-growing districts in Far North Queensland differs markedly from those in the other maize-growing regions. Despite their tropical latitude $\left(17^{\circ} \mathrm{S}.\right)$, most districts have moderate temperatures, since they are elevated on 
either the Atherton $(750 \mathrm{~m})$, Mareeba (300 m) or Evelyn (900 m) Tablelands. Rain falls predominantly in summer and is more reliable and can be several times greater than in the other maize-growing regions. In Far North Queensland the crop is sown from November to January, depending on and following the onset of the seasonal storm rains. During the growing period it is subjected to high humidity and wet weather which may continue into the winter months, particularly in districts on the Atherton and Evelyn Tablelands (Crosthwaite 1983). This weather pattern is very conducive to the development of fungal diseases of maize, and these fungi are a potential source of mycotoxins. We report here the first survey of maize from this region for mycotoxins, carried out in a season with a typical distribution of rainfall.

\section{Materials and Methods}

Selection of Mycotoxins for Maize Assay

Methods used in this survey were designed to detect the following mycotoxins: afiatoxins $B_{1}, B_{2}, G_{1}$ and $\mathrm{G}_{2}$; ochratoxin $A$; zearalenone; sterigmatocystin; $T-2$ toxin. This selection was partly dictated by the mycotoxin standards that were available. However, $G$. zeae is frequently found on the Atherton Tableland, causing a stalk and cob rot of maize (Pont 1963), while it is rarely encountered on the Darling Downs (Purss 1969). The inclusion of zearalenone and T-2 toxin was therefore important as these can both be produced in Gibberella-damaged maize. Aflatoxins have been detected in peanuts grown on the Atherton Tableland, and also in maize from the Burnett (Blaney 1981). Ochratoxin A has been found in a sample of mouldy bread from the tropical coast adjacent to the Atherton Tableland (Connole et al. 1981) and in one sorghum sample from the Burnett region (Ketterer et al. 1982). Sterigmatocystin has not been recorded in Australia, but its presence has been surveyed, as it is carcinogenic and a precursor of the aflatoxins.

\section{Sampling Procedure}

All maize produced on the Atherton Tableland is required, by regulation, to be delivered to the Atherton Tableland Maize Marketing Board. This Board operates drying and storage facilities at Atherton and Tolga, and also has storage silos at Kairi. During intake of the 1982 crop at the Atherton silos, truck deliveries of maize were sampled from the stream as the loads were tipped into the grain elevator. Sampling started midway through the 1982 intake. After their moisture content was determined, samples were placed in paper bags and sent to the laboratory in Brisbane.

\section{Rapid Screening Tests for Fungal Damage}

On receipt at the laboratory, the samples were weighed and then spread out on a tray. Kernels with obvious mould damage were counted. Nearly all of these had a pronounced reddish-purple or brownishpurple discoloration, usually with some shrivelling. This discoloration is typically caused by $G$. zeae cob rot (Pont 1963). Based on this visual appraisal, the samples were categorized into groups containing $<5$, 5-20 or 20-40 Gibberella-damaged kernels (GDK) per sample. On the basis of either number or weight proportions, this closely approximated $<0.25 \%, 0.25-1.00 \%$ or $1.00-2 \cdot 00 \%$ of the sample respectively. The samples were then cracked in a maize cracker and examined under long-wavelength $(366 \mathrm{~nm})$ ultraviolet (UV) illumination for the presence of bright greenish-yellow (BGY) fluorescent particles (Fennell et al. 1973), which indicates damage by some Aspergillus spp. and possibly other fungi. The number of such particles was recorded.

\section{Mult-mycotoxin Screening Method}

The multi-mycotoxin screening method used was adapted from that of Patterson and Roberts (1979). After completion of the rapid screening tests, the samples were hammermilled through a $1-\mathrm{mm}$ screen. Subsamples of $25 \mathrm{~g}$ were shaken for 30 min with $102 \mathrm{ml}$ of a mixture of distilled acetonitrile $: 4 \%$ aqueous potassium chloride $5 \mathrm{M}$ hydrochloric acid $(90: 10: 2, \mathrm{v} / \mathrm{v} / \mathrm{v})$. After filtration, $50 \mathrm{ml}$ of filtrate was added to $50 \mathrm{ml}$ of water contained in a separatory funnel and fat was extracted with $2 \times 50-\mathrm{ml}$ distilled hexane. The hexane extracts were discarded and the acetonitrile phase was extracted twice with 50-ml portions of distilled methylene chloride. The methylene chloride extracts were passed in sequence through a $2-\mathrm{cm}$-diameter column (10 $\mathrm{cm}$ long) of anhydrous sodium sulfate. The dried methylene 
chloride extracts were then evaporated to dryness under an air stream over a steam bath. The residue was redissolved in $0.2 \mathrm{ml}$ of methylene chloride, and $10 \mu \mathrm{l}$ of this was applied near to one corner of a 10 by $10 \mathrm{~cm}$ thin-layer chromatographic aluminium sheet, pre-coated with silica gel 60 (E. Merck, Darmstadt, F.R.G.). The sheets were developed two-dimensionally; first in chloroform : acetone $(9: 1$, $\mathrm{v} / \mathrm{v})$ and then in toluene : ethyl acetate : formic acid $(5: 4: 1, \mathrm{v} / \mathrm{v} / \mathrm{v})$.

Aflatoxins $B_{1}, B_{2}, G_{1}$ and $G_{2}$ were visible as blue $\left(B_{1}\right.$ and $\left.B_{2}\right)$ or blue-green $\left(G_{1}\right.$ and $\left.G_{2}\right)$ spots when viewed under long-wavelength UV light. Their $R_{F}$ values were $0.62,0.56,0.48$ and 0.40 respectively in the first dimension, and $0.22,0.20,0.15$ and 0.12 respectively in the second dimension.

Ochratoxin A was visible as a blue spot under long-wavelength UV light with an $R_{\mathrm{F}}$ of 0.00 in the first dimension and 0.46 in the second dimension.

Zearalenone was visible as a pale blue spot which was more intense when viewed under shortwavelength UV than under long-wavelength UV light, with an $R_{\mathrm{F}}$ of 0.90 in the first dimension, and 0.57 in the second.

Sterigmatocystin had an $R_{\mathrm{F}}$ of 1.00 in the first dimension and 0.57 in the second dimension. At high concentrations it was a dull red spot under long-wavelength $U V$, but produced a more intense orange spot under long-wavelength UV light, immediately upon spraying with a $20 \%$ aqueous solution of potassium hydroxide.

The T-2 toxin had an $R_{\mathrm{F}}$ of 0.40 in the first dimension and 0.33 in the second dimension. It became visible as a pale green spot under long-wavelength UV illumination only after spraying with a $20 \%$ solution of sulfuric acid in ethanol, and heating at $100^{\circ} \mathrm{C}$ for $5 \mathrm{~min}$.

Detection limits of the method were $0.01 \mathrm{mg} \mathrm{kg}^{-1}$ zearalenone, $0.005 \mathrm{mg} \mathrm{kg}^{-1}$ total aflatoxins, $0.005 \mathrm{mg} \mathrm{kg}^{-1}$ ochratoxin $\mathrm{A}, 0.02 \mathrm{mg} \mathrm{kg}^{-1}$ sterigmatocystin and $0.1 \mathrm{mg} \mathrm{kg}^{-1} \mathrm{~T}-2$ toxin.

\section{Quantification of Zearalenone}

Zearalenone was quantified by use of a high performance liquid chromatographic procedure. Suitable aliquots of the methylene chloride solution remaining from the thin-layer chromatography procedure were applied to a silica Sep-pak (Waters Associates, Inc., Milford, U.S.A.) previously flushed with chloroform, and the zearalenone was eluted with chloroform. The first $3 \mathrm{ml}$ of eluate were discarded; the next $11 \mathrm{ml}$ were collected, evaporated to dryness in an air stream over a steam bath, and the residue redissolved in $200 \mu \mathrm{l}$ methanol. Aliquots $(10 \mu \mathrm{l})$ of this solution were analysed by reversedphase high-performance liquid chromatography. The instrument used was a Spectra-Physics $8000 \mathrm{~B}$ highperformance liquid chromatograph, fitted with a F.S.970 fluorescence detector, and a Merck Hibar C-18 column operated at $35^{\circ} \mathrm{C}$. The mobile phase was a mixture of methanol : water $(3: 1, v / v)$ with a flow rate of $2 \mathrm{ml} \mathrm{min}^{-1}$. The detector was fitted with a $418 \mathrm{~nm}$ emission filter, with excitation at $236 \mathrm{~nm}$.

\section{Results}

\section{Sampling}

In all, 293 samples of maize from 111 growers were examined; 203 growers grew $\geqslant 8$ ha maize in 1981-82 in Far North Queensland (Australian Bureau of Statistics), and so about half of these were represented in our survey. Maize is grown in eight major districts in the region, and these districts differ markedly in altitude and average rainfall. District 1 is in the drier south-west of the tableland region. Districts 2-7 lie at gradually decreasing altitudes on either the Evelyn, Atherton or Mareeba Tablelands, while district 8 lies about $150 \mathrm{~km}$ to the north of the other districts. The proportions of samples originating in each of these districts are compared in Table 1 with the total maize produced in each district as estimated by seed sales to growers in the districts. From Table 1, districts 1,2 and 3 were slightly over-represented at the expense of drier districts 6,7 and 8. This came about because sampling commenced midway through the harvest, and there is a tendency for earlier harvest in the drier districts.

The mean \pm s.d. $(n=293)$ sample weight was $0.82 \pm 0.097 \mathrm{~kg}$ and the mean moisture content of these samples was $16 \cdot 4 \pm 0 \cdot 85 \%$ when this was measured at Atherton. 
Table 1. Maize samples received from different districts compared with seed sales in each district

\begin{tabular}{|c|c|c|c|}
\hline Locality & $\begin{array}{l}\text { District } \\
\text { No }\end{array}$ & $\begin{array}{l}\text { Seed sales } \\
(\% \text { of total })\end{array}$ & $\begin{array}{l}\text { Samples } \\
(\% \text { of total) }\end{array}$ \\
\hline $\begin{array}{l}\text { Innot Hot Springs, Mount Garnet, Herberton, } \\
\text { Kaban, Tumoulin, Ravenshoe }\end{array}$ & 1,2 & 15 & 23 \\
\hline Malanda, Upper Barron, East Barron, Peeramon & 3 & $9 \cdot 5$ & 17 \\
\hline Kairi, Yungaburra & 4 & 22 & 20 \\
\hline Atherton, Tolga & 5 & 25 & 27 \\
\hline Rocky Creek, Walkamin & 6 & $9 \cdot 5$ & 3 \\
\hline Dimbulah, Mareeba, Emerald Creek, Davies Creek & 7 & 8 & 4 \\
\hline Lakeland Downs & 8 & 11 & 6 \\
\hline
\end{tabular}

\section{Rapid Screening Tests}

Most of the samples contained BGY positive particles, with $30 \%$ containing more than five particles per sample. However, in many samples there were large amounts of extraneous and assorted fluorescences associated with mould damage which made identification of BGY particles difficult. There was some correlation between

Table 2. Number of maize samples from each district having different percentages of Gibberelladamaged kernels (GDK) and the corresponding zearalenone concentrations in these samples

\begin{tabular}{|c|c|c|c|c|c|c|c|}
\hline \multirow[t]{2}{*}{$\begin{array}{l}\text { District } \\
\text { No. }\end{array}$} & \multirow{2}{*}{ Locality } & \multicolumn{3}{|c|}{$\begin{array}{l}\text { No. of samples containing } \\
\text { different percentages of GDK }\end{array}$} & \multicolumn{3}{|c|}{$\begin{array}{l}\text { Mean zearalenone concn } \\
\left(\mathrm{mg} \mathrm{kg}^{-1}\right) \text { in the samples }\end{array}$} \\
\hline & & $<0.25$ & $0 \cdot 25-1 \cdot 00$ & $1 \cdot 00-2 \cdot 00$ & $<0.25$ & $0 \cdot 25-1 \cdot 00$ & $1 \cdot 00-2 \cdot 00$ \\
\hline \multirow[t]{2}{*}{1} & Innot Hot Springs & 2 & & & 0.02 & & \\
\hline & Mount Garnet & 10 & & & 0.01 & & \\
\hline \multirow[t]{4}{*}{2} & Herberton & 1. & 6 & 2 & 0.16 & 0.11 & $0 \cdot 14$ \\
\hline & Kaban & 14 & 17 & 8 & 0.03 & $0 \cdot 12$ & 0.27 \\
\hline & Tumoulin & & 1 & & & $0 \cdot 28$ & \\
\hline & Ravenshoe & & 4 & 2 & & $0 \cdot 29$ & 0.44 \\
\hline \multirow[t]{4}{*}{3} & Malanda & 1 & 7 & 7 & 0.03 & $0 \cdot 25$ & $0 \cdot 49$ \\
\hline & Upper Barron & 2 & 4 & 9 & 0.09 & $0 \cdot 18$ & 0.62 \\
\hline & East Barron & 3 & 3 & 6 & 0.06 & $0 \cdot 29$ & $0 \cdot 78$ \\
\hline & Peeramon & & 6 & 2 & & $0 \cdot 30$ & 0.59 \\
\hline \multirow[t]{2}{*}{4} & Kairi & 6 & 8 & 9 & 0.05 & 0.06 & $0 \cdot 18$ \\
\hline & Yungaburra & 8 & 22 & 7 & 0.05 & $0 \cdot 17$ & $0 \cdot 20$ \\
\hline \multirow[t]{2}{*}{5} & Atherton & 28 & 33 & 10 & 0.08 & $0 \cdot 13$ & 0.48 \\
\hline & Tolga & 4 & 3 & & 0.02 & 0.08 & \\
\hline \multirow[t]{2}{*}{6} & Rocky Creek & 1 & 5 & 1 & 0.01 & 0.05 & 0.40 \\
\hline & Walkamin & 1 & & & A & & \\
\hline \multirow[t]{4}{*}{7} & Dimbulah & 3 & & & 0.01 & & \\
\hline & Mareeba & 4 & & & $A$ & & \\
\hline & Emerald Creek & 3 & & & A & & \\
\hline & Davies Creek & 3 & & & 0.01 & & \\
\hline 8 & Lakeland Downs & 17 & & & 0.04 & & \\
\hline
\end{tabular}

A Mean zearalenone concentration $<0.005 \mathrm{mg} \mathrm{kg}^{-1}$.

samples with large numbers of BGY particles and those with large numbers of GDK. However, kernels with the most obvious reddish-purple discoloration did not usually display BGY fluorescence. Proportions of GDK showed similarities within districts and differences between districts. These data are shown in Table 2. 


\section{Multi-mycotoxin Screening}

Only zearalenone was detected, but this was present in $85 \%$ of the samples. One sample from Upper Barron, two from East Barron and one from Atherton exceeded $1 \mathrm{mg}$ zearalenone $\mathrm{kg}^{-1}\left(1 \cdot 05,1 \cdot 11,1 \cdot 12\right.$ and $1 \cdot 51 \mathrm{mg} \mathrm{kg}^{-1}$ respectively). The mean \pm s.d. $(n=293)$ concentration in all samples assayed was $0 \cdot 17 \pm 0 \cdot 225$ $\mathrm{mg} \mathrm{kg}^{-1}$.

Table 3. Means or medians of all available meteorological data for stations within each district for the maize-growing period

\begin{tabular}{|c|c|c|c|c|c|c|c|c|c|}
\hline $\begin{array}{c}\text { District } \\
\text { No. }\end{array}$ & $\begin{array}{c}\text { Meteorology } \\
\text { station } \\
\text { (elevation) }\end{array}$ & Parameter & Jan. & Feb. & Mar. & Apr. & May & Jun. & Total \\
\hline \multirow[t]{2}{*}{1} & Mount Garnet & Rainfall $^{\mathrm{A}}$ & 166 & 162 & 133 & 26 & 14 & 12 & 513 \\
\hline & $(671 \mathrm{~m})$ & Raindays $^{B}$ & 12 & 12 & 10 & 6 & 5 & 4 & 49 \\
\hline \multirow[t]{3}{*}{2} & Herberton & Rainfall & 211 & 227 & 174 & 60 & 39 & 24 & 734 \\
\hline & $(899 \mathrm{~m})$ & Raindays & 16 & 16 & 16 & 14 & 12 & 9 & 83 \\
\hline & & Temperature $^{C}$ & $23 \cdot 1$ & $22 \cdot 8$ & $21 \cdot 9$ & $20 \cdot 1$ & $18 \cdot 0$ & $16 \cdot 1$ & \\
\hline \multirow[t]{2}{*}{3} & Malanda & Rainfall & 255 & 324 & 263 & 139 & 92 & 56 & 1129 \\
\hline & $(762 \mathrm{~m})$ & Raindays & 17 & 18 & 19 & 17 & 16 & 13 & 100 \\
\hline \multirow[t]{3}{*}{4} & Kairi & Rainfall & 220 & 234 & 204 & 78 & 54 & 34 & 824 \\
\hline & $(715 \mathrm{~m})$ & Raindays & 17 & 17 & 18 & 16 & 13 & 10 & 91 \\
\hline & & Temperature & $23 \cdot 5$ & $23 \cdot 4$ & $22 \cdot 4$ & $20 \cdot 6$ & $18 \cdot 7$ & $16 \cdot 5$ & \\
\hline \multirow[t]{2}{*}{5} & Atherton & Rainfall & 204 & 239 & 241 & 106 & 56 & 30 & 876 \\
\hline & $(752 \mathrm{~m})$ & Raindays & 17 & 20 & 18 & 18 & 14 & 9 & 96 \\
\hline \multirow[t]{3}{*}{6} & Walkamin & Rainfall & 181 & 219 & 207 & 43 & 18 & 19 & 687 \\
\hline & $(591 \mathrm{~m})$ & Raindays & 16 & 18 & 17 & 12 & 9 & 7 & 79 \\
\hline & & Temperature & $25 \cdot 0$ & $24 \cdot 6$ & $23 \cdot 9$ & $22 \cdot 1$ & $20 \cdot 4$ & $18 \cdot 5$ & \\
\hline \multirow[t]{3}{*}{7} & Mareeba & Rainfall & 188 & 227 & 156 & 33 & 20 & 9 & 633 \\
\hline & $(335 \mathrm{~m})$ & Raindays & 16 & 17 & $\therefore 16$ & 11 & 7 & 5 & 72 \\
\hline & & Temperature & $26 \cdot 0$ & $25 \cdot 9$ & $24 \cdot 8$ & $23 \cdot 0$ & $21 \cdot 0$ & $18 \cdot 8$ & \\
\hline \multirow[t]{2}{*}{8} & Butcher Hill & Rainfall & 253 & 228 & 161 & 22 & 4 & 4 & 672 \\
\hline & (c. $300 \mathrm{~m})$ & Raindays & 13 & 14 & 10 & 4 & 2 & 2 & 45 \\
\hline
\end{tabular}

A Median of all available years of rainfall records $(\mathrm{mm})$.

${ }^{B}$ Mean of all available years of records for number of days on which measurable rainfall occurred.

C Mean of mean daily maximum and minimum temperatures $\left({ }^{\circ} \mathrm{C}\right)$. Data were unavailable for districts $1,3,5$ and 8 .

\section{Variation in Zearalenone Concentrations}

The data in Table 2 show a correlation between zearalenone concentrations and the proportions of GDK in the samples. There were marked differences in zearalenone concentrations between districts. Since mean temperature and the amount and timing of rainfall are considered to influence the incidence of Gibberella cob rot, meteorological data during the maize growing period from all recording stations in the region are presented in Tables 3 and 4.

\section{Discussion}

\section{Bright-Greenish Yellow Fluorescence and Aflatoxin}

It has been demonstrated (Blaney 1981) that a rapid BGY test, based on selecting maize samples containing more than five particles of cracked maize per $2 \mathrm{~kg}$ 
sample, is suitable for identifying samples likely to contain $>0.02 \mathrm{mg} \mathrm{kg}^{-1}$ total aflatoxins in the Burnett region. This test has been successfully used by the Queensland Grain Growers Association in subsequent surveys in the Burnett region. In 1978, eight samples from 805 maize deliveries were found to contain $>0.02 \mathrm{mg} \mathrm{kg}^{-1}$ total aflatoxins (Blaney 1981) and out of 768 deliveries from the drought-affected $1980 \mathrm{crop}, 28$ samples contained more than $0.02 \mathrm{mg} \mathrm{kg}^{-1}$ total aflatoxins (J. G. Twyford, personal communication).

Table 4. Meteorological data for stations within each district for the maize-growing period of 1982

\begin{tabular}{|c|c|c|c|c|c|c|c|c|c|}
\hline $\begin{array}{l}\text { District } \\
\text { No. }\end{array}$ & $\begin{array}{l}\text { Meteorology } \\
\quad \text { station }\end{array}$ & Parameter & Jan. & Feb. & Mar. & Apr. & May & Jun. & Total \\
\hline \multirow[t]{2}{*}{1} & Mount Garnet & Rainfall (mm) & 106 & 45 & 59 & 90 & 10 & 11 & 321 \\
\hline & & Raindays $^{\mathrm{A}}$ & 10 & 10 & 12 & 13 & 8 & 3 & 56 \\
\hline \multirow[t]{3}{*}{2} & Herberton & Rainfall & 220 & 144 & 162 & 238 & 36 & 19 & 819 \\
\hline & & Raindays & 15 & 16 & 23 & 21 & 12 & 8 & 95 \\
\hline & & Temperature $^{\mathrm{B}}$ & $23 \cdot 8$ & $23 \cdot 3$ & $22 \cdot 3$ & $20 \cdot 2$ & $17 \cdot 4$ & $13 \cdot 6$ & \\
\hline \multirow[t]{2}{*}{3} & Malanda & Rainfall & 207 & 224 & 198 & 435 & 52 & 29 & 1145 \\
\hline & & Raindays & 10 & 14. & 17 & 20 & 7 & $(13)^{C}$ & 81 \\
\hline \multirow[t]{3}{*}{4} & Kairi & Rainfall & 251 & 137 & 172 & 258 & 41 & 23 & 882 \\
\hline & & Raindays & 19 & 22 & 22 & 23 & 11 & 7 & 104 \\
\hline & & Temperature & $24 \cdot 0$ & $23 \cdot 4$ & $22 \cdot 8$ & $20 \cdot 5$ & $17 \cdot 7$ & $14 \cdot 0$ & \\
\hline \multirow[t]{2}{*}{5} & Atherton & Rainfall & 244 & 111 & 107 & 211 & 52 & 14 & 739 \\
\hline & & Raindays & 15 & 16 & 20 & 20 & 12 & 5 & 88 \\
\hline \multirow[t]{3}{*}{6} & Walkamin & Rainfall & 228 & 111 & 118 & 85 & 16 & 8 & 566 \\
\hline & 2 & Raindays & 14 & 16 & 16 & 16 & 11 & 5 & 78 \\
\hline & & Temperature & $25 \cdot 3$ & $25 \cdot 0$ & $24 \cdot 0$ & $21 \cdot 9$ & $19 \cdot 6$ & $16 \cdot 3$ & \\
\hline \multirow[t]{3}{*}{7} & Mareeba & Rainfall & 159 . & 101 & 122 & 81 & 12 & 4 & 479 \\
\hline & & Raindays & 13 & 16 & 17 & 14 & 9 & 2 & 71 \\
\hline & & Temperature & $26 \cdot 9$ & $26 \cdot 0$ & $25 \cdot 7$ & $(23 \cdot 0)^{C}$ & $20: 2$ & $16 \cdot 6$ & \\
\hline 8 & & There was $n$ & station & in this & strict d & uring 198 & & & \\
\hline
\end{tabular}

A Number of days on which measurable rainfall occurred.

${ }^{\mathrm{B}}$ Mean of mean daily maximum and minimum temperatures $\left({ }^{\circ} \mathrm{C}\right)$. Data were unavailable for districts 1,3 and 5 .

${ }^{C}$ Data were unavailable. Values in parenthesis are means of all available records.

In the present investigation, $30 \%$ of the samples contained more than five BGYpositive particles and, in addition, these samples were much smaller than the 2-kg samples used by Blaney (1981). The complete absence of aflatoxin from the samples suggests that either the BGY fluorescence was produced by some fungus other than $A$. flavus, or that the A. flavus was non-toxigenic, at least under the climatic conditions prevailing during growth of this crop. Both toxigenic and non-toxigenic A. flavus have been isolated from maize samples from this region (M. D. Connole, personal communication). This situation may be comparable with that in Indiana, U.S.A., where $A$. flavus is rare in undamaged preharvest maize, either because of competition from other fungi or because climatic conditions are not as suitable for A. flavus as in the south-eastern U.S.A. (Rambo et al. 1974). Nevertheless, it cannot be assumed that aflatoxin contamination of maize will never be a problem in Far North Queensland, particularly in the drier districts such as district 1; more surveys are required. It appears that the rapid BGY test will be unsuitable for screening maize from this region. 


\section{The Correlation between the Extent of Gibberella Cob Rot and Zearalenone Concentrations}

All maize hybrids grown in Far North Queensland were developed for the region by the Queensland Department of Primary Industries at Kairi Research Station. One of the selected characteristics is resistance to Gibberella cob rot. The maximum percentage of about $2 \%$ GDK found in the present survey is in agreement with the average percentage of diseased grain obtained in trials at Kairi for the hybrids QK690, QK694 and QK657 of 1·7, 1 2 and 2.4, respectively (I. F. Martin, personal communication). These three hybrids comprised the bulk of maize grown in all districts and no differences between them in either incidence of GDK or zearalenone concentration could be determined in the present survey.

The observed correlation (Table 2) between the proportions of GDK and concentrations of zearalenone indicates this to be a useful rapid screening test for selecting samples most likely to contain zearalenone. However, it does not prove that all of the zearalenone was produced by $G$. zeae. Several other fungi reported to produce zearalenone have been isolated in the region, particularly $G$. fujikuroi (Saw.) Wr. (F. moniliforme Sheldon) (Francis and Burgess 1975) which may also have been present.

Concentrations of zearalenone in some individual samples exceeded $1 \mathrm{mg} \mathrm{kg}^{-1}$, a concentration which is known to cause pseudo-oestrogenism in prepubertal gilts (Kurtz et al. 1969). However, the normal practice of the Atherton Tableland Maize Marketing Board is to dry the maize to below $14 \%$ moisture content, which should inhibit fungal growth, and the bulking process would tend to reduce the overall concentration of zearalenone to below that known to cause biological effects. On the other hand, on-farm storage of Gibberella-damaged maize at a high moisture content has lead to zearalenone intoxication of pigs in the region (Blaney et al. 1984). Upper Barron, where these cases occurred, had among the highest proportions of GDK in the present survey.

\section{Factors affecting the Extent of Gibberella Cob Rot and Mycotoxin Contamination}

Apart from hybrid resistance, factors that may influence the extent of Gibberella cob rot include weed proliferation, insect damage, crop rotations and carryover of crop residues between seasons (Crosthwaite 1983). Possibly the major factor is climate.

Information gained during the Gibberella cob rot epidemics in Indiana (Tuite et al. 1974) suggested that conditions favouring an outbreak were a minimum of 7 days of rain and mean temperatures below $22 \cdot 8^{\circ} \mathrm{C}$ during the 21 -day maize silking period. A severe outbreak was favoured by 9 days of rain and mean temperatures below $21 \cdot 1^{\circ} \mathrm{C}$ during silking. Sutton et al. (1980) found that the incidence of zearalenone-positive maize samples from southern Ontario, Canada, correlated most strongly with excessive rainfall during the period of silking, rather than with rainfall during other stages of maize growth. They also found that the correlation between the incidence of zearalenone-positive samples and temperatures was weak.

From the meteorological data from all previous years' records given in Table 3 , it is very likely that most districts in Far North Queensland typically have more than 10 days of rain during the 21-day silking period, whether this occurs in February, March or April. The exceptions are Mount Garnet (district 1) and Butcher Hill (district 8). In addition, with the same exceptions, total rainfall during 
these months is usually similar to, or higher than, that received in southern Ontario in seasons with higher incidences of zearalenone-positive maize cobs.

The 1982 rainfall pattern (Table 4) was regarded as fairly typical, given the extremes that occur in this region. Practically all plantings were completed in December 1981, maize growth was satisfactory and final crop yields were above average (I. F. Martin, personal communication). Nevertheless, while rainfall during the main silking period in late February and early March was slightly below the median, April rainfall was much higher than the median rainfall for the region.

We found that districts $2(22 \%), 3(47 \%)$ and $4(39 \%)$ had the greatest proportions of samples with $1-2 \%$ GDK. These districts had more rainfall than others during the silking period in February or March. In addition, they also had the highest rainfall in April, with district 3 receiving by far the most. This very high rainfall during maize maturation in district 3 may explain the highest concentration of zearalenone in samples with 1-2\% GDK from this district. However, persistent wetness and shortage of harvesters can delay harvesting in this district and such delays may also have contributed.

The investigations by Tuite et al. (1974) and Sutton et al. (1980) have primarily directed attention to factors influencing the incidence of moulded maize cobs and thus relate to the infection process. These factors include insect and bird damage, as well as weather variables (Sutton 1982). However, once infection of a cob has taken place, the extent to which the cob is moulded and mycotoxins produced may be influenced by factors additional to these. In the tableland districts in Far North Queensland, weather conditions are nearly always favourable for $G$. zeae infection and growth. The extent to which this occurs may depend primarily on slight differences in hybrid resistance, insect damage and competition with other fungi.

\section{Trichothecene Toxins produced by G. zeae}

While pseudo-oestrogenism in pigs (presumably caused by zearalenone) was reported during the cob rot epidemics in Indiana (Tuite et al. 1974), its effects were completely overshadowed by refusal of stock (particularly pigs) to consume the Gibberella-damaged maize. The feed refusal factor, which also causes emesis, has been shown by Vesonder et al. (1976) to be a trichothecene toxin, deoxynivalenol, and both zearalenone and deoxynivalenol can be produced by some isolates of $F$. graminearum (Vesonder et al. 1981). At present, we do not know whether deoxynivalenol or other trichothecenes were present in our maize samples or indeed whether they are produced by Australian isolates of $F$. graminearum. In the cases of pseudo-oestrogenism reported by Blaney et al. (1984), no feed refusal was detected in pigs fed on maize containing c. $20 \%$ GDK. Tuite et al. (1974) reported that the concentration of GDK in samples from some regions in the United States of America was not related to the severity of feed refusal. The most important factor predisposing to deoxynivalenol production may be temperature, but the limited data available (Table 3 ) indicate that only if the silking period were to extend into late-April on the tablelands, would the temperatures during the silking period approximate those recorded by Tuite et al. (1974) as favouring an outbreak of feed refusal.

\section{Conclusions}

The results indicate that mycotoxin contamination of maize is unlikely to be a problem in Far North Queensland under normal circumstances. However, 
Gibberella cob rots are common in some districts. This indicates a possible risk of increased contamination by mycotoxins produced by Gibberella spp. if climatic or other factors are less favourable than in the 1982 season.

Mycotoxin surveys should be repeated in this region in subsequent seasons, when either rainfall is unusually high or maize planting is delayed. Deoxynivalenol should be included in these surveys. More data are also needed on the fungi involved in cob rots in the region and their interrelationship during seasons with various rainfall distributions.

\section{Acknowledgments}

The Atherton Tableland Maize Marketing Board collaborated in this investigation and provided the samples. Our thanks go particularly to I. C. Crosthwaite who provided much information on maize-growing in the region and to I. F. Martin who provided samples of Gibberella-damaged maize cobs.

\section{References}

Blaney, B. J. (1981). Aflatoxin survey of maize from the 1978 crop in the South Burnett region of Queensland. Queensl. J. Agric. Anim. Sci. 38, 7-12.

Blaney, B. J., Bloomfield, R. C., and Moore, C. J. (1984). Zearalenone intoxication of pigs. Aust. Vet. J. 61, 24-7.

Brown, R. H. (1977). Widespread aflatoxin presence found in southern corn crop. Feedstuffs 49 (37), 1.

Connole, M. D., Blaney, B. J., and McEwan, T. (1981). Mycotoxins in animal feeds and toxic fungi in Queensland 1971-80. Aust. Vet. J. 57, 314-18.

Crosthwaite, I. C. (1983). Maize growing on the Atherton Tableland. Queensl. Agric. J. 109, 40-6.

Fennell, D. I., Bothast, R. J., Lillehoj, E. B., and Peterson, R. E. (1973). Bright greenish-yellow fluorescence and associated fungi in white corn naturally contaminated with aflatoxin. Cereal Chem. 50, 404-14.

Francis, R. G., and Burgess, L. W. (1975). Surveys of Fusaria and other fungi associated with stalk rot of maize in eastern Australia. Aust. J. Agric. Res. 26, 801-7.

Ketterer, P. J., Blaney, B. J., Moore, C. J., McInnes, I. S., and Cook, P. W. (1982). Field cases of aflatoxicosis in pigs. Aust. Vet. J. 59, 113-17.

Kurtz, H. J., Nairn, M. E., Nelson, G. H., Christensen, C. M., and Mirocha, C. J. (1969). Histological changes in the genital tracts of swine fed estrogenic mycotoxin. Am. J. Vet. Res. 30, 551-6.

Patterson, D. S. P., and Roberts, J. (1979). Mycotoxins in animal feedstuffs: sensitive thin-layer chromatographic detection of aflatoxin, ochratoxin A, sterigmatocystin, zearalenone and T-2 toxin. J. Assoc. Off. Anal. Chem. 62, 1265-7.

Pont, W. (1963). Maize diseases are common in North Queensland. Queensl. Agric. J. 89, 357-65.

Purss, G. S. (1969). The relationship between strains of Fusarium graminearum Schwabe causing crown rot of various gramineous hosts and stalk rot of maize in Queensland. Aust. J. Agric. Res. 20, 257-64.

Rambo, G. W., Tuite, J., and Caldwell, R. W. (1974). Aspergillus flavus and aflatoxin in preharvest corn from Indiana in 1971 and 1972. Cereal Chem. 51, 595-604.

Sutton, J. C. (1982). Epidemiology of wheat head blight and maize ear rot caused by Fusarium graminearum. Can. J. Plant Pathol., 4, 195-209.

Sutton, J. C., Baliko, W., and Funnell, H. S. (1980). Relation of weather variables to incidence of zearalenone in corn in southern Ontario. Can. J. Plant Sci. 60, 149-55.

Tuite, J., Shaner, G., Rambo, G., Foster, J., and Caldwell, R. W. (1974). The gibberella ear rot epidemics of corn in Indiana in 1965 and 1972. Cereal Sci. Today 19, 238-41.

Vesonder, R. F., Ciegler, A., Jensen, A. H., Rohwedder, W. K., and Weisleder, D. (1976). Co-identity of the refusal and emetic principle from Fusarium-infected corn. Appl. Environ. Microbiol. 31, $280-5$.

Vesonder, R. J., Ellis, J. J., and Rohwedder, W. K. (1981). Elaboration of vomitoxin and zearalenone by Fusarium isolates and the biological activity of Fusarium-produced toxins. Appl. Environ. Microbiol. 42, 1132-4. 